\title{
PEEL BOND STRENGTH BETWEEN A SILICONE-BASED SOFT LINER AND A HEAT-CURED ACRYLIC RESIN DENTURE BASE REINFORCED WITH THREE CONCENTRATIONS OF METAL OXIDE NANOPARTICLES
}

\author{
Mohammed Shawky El-Naggar*, \\ Osama Abdel-Monaem Baraka** and Ahmad Mohamed Shoeib***
}

\begin{abstract}
Purpose: To evaluate the effect of incorporation of $0.1 \%, 0.3 \%$, and $0.5 \%$ concentrations of titanium oxide, aluminum oxide, and silica nanoparticles in the heat-cured acrylic resin denture base on the peel bond strength to a silicone denture liner.

Methods: A total number of 100 heat-cured acrylic resin samples were prepared and classified into a control group and three groups according to the type of nanoparticle. Each group was classified into three subgroups according to the concentration of the nanoparticle $(n=10)$. A Silicone based-soft liner was added over the acrylic resin specimens, and the peel bond strength was measured using the peeling bond strength test at an angle of $90^{\circ}$. Statistical analysis was done using a Two-way ANOVA test for interactions between peel bond strength and the different nanoparticle materials and their concentrations.
\end{abstract}

Results: Two-way ANOVA showed that the three nanoparticles and different concentrations did not affect the peel bond strength.

Conclusion: The nanoparticles in this study were not effective in increasing peel bond strength at the studied concentrations.

KEYWORDS: Nanoparticles, Denture base, Heat cured, Peel bond strength, Silicon soft liner.

\footnotetext{
* Ministry of Health and Population, Aga, Daqahleya, Egypt

** Professor of Removable Prosthodontics, Faculty of Dental Medicine for boys, Al-Azhar University, Cairo, Egypt. *** Lecturer of Removable Prosthodontics, Faculty of Dental Medicine, Al-Azhar University, Cairo, Egypt
} 


\section{INTRODUCTION}

Soft lining products have been used to solve many clinical problems associated with the use of acrylic resin denture base. These materials can evenly distribute the functional load on the denturebearing area and avoid load stress concentration. They also increase the adaptation and retention of the complete denture when bone resorption occurs ${ }^{[1]}$. Dentures with soft liners have been documented to be easier to use with significant improvements in the articulation, masticatory effectiveness, denture retention and stability, reduced pain sensitivity and oral ulcers under the dentures, and improved comfort and length of denture usage ${ }^{[2]}$. Several types of soft liners are used in many prosthetic applications. Soft liners are either acrylic resin or silicone-based. These groups are available in either auto polymerized or heat-polymerized forms ${ }^{[3]}$. Silicone-based soft liner materials are made from dimethylsiloxane polymers that are cross-linked to form a rubber characterized by a reasonable elastic property ${ }^{[4]}$.

Soft liners face some clinical problems such as the failure of bonding between the soft liner and the denture base, loss of durability, tearing, and also color change ${ }^{[5]}$. Bond failure is one of the main problems that make the liner surface susceptible to fungal and bacterial growth. Bond failure leads to plaque and calculus formation, oral tissue infection, and material degradation ${ }^{[6]}$. Plaque accumulation can cause systemic diseases as bacterial endocarditis, pneumonia, oropharyngeal, esophageal, and respiratory infections. Contamination of soft liner in implant overdenture may cause peri-implantitis and bone loss ${ }^{[7]}$. The absence of adequate bonding to the denture base materials will affect the desired properties of soft liner. Many factors affect the strength of the bond as water absorption, the composition of the denture base and denture liner, and the addition of primer ${ }^{[8]}$.

The bonding between the acrylic-resin soft liners and the acrylic-resin denture base showed greater values than the silicone based-soft liner. The bond strength decreases with the length of water storage, which was more in the acrylic-resin soft liners ${ }^{[9]}$. The bond strength decreases due to the different chemical composition of the silicone-based-soft liner and the acrylic resin denture. Therefore, an adhesive primer is needed to improve the bond strength between them. It has an organic solvent that interacts with both silicone and the acrylic-resin and improves hydrogen bonding between them and covalent coupling. It also increases the wettability of the acrylic resin denture ${ }^{[10]}$. The bond efficiency between the silicone-soft liners and the acrylic resin using different bonding agents showed that the primer addition is more compatible with the silicone based-soft liner ${ }^{[11]}$. Improve bond will increase the durability of the maxillofacial prosthesis. It was found that the bonding of the silicone based-liner to the acrylic-resin was improved by the addition of a commercial primer containing methyl ethyl ketone and dichloromethane solvent ${ }^{[12]}$. Surface treatment with the monomer showed an increase in the acrylic resin soft liner's bond strengths, but not for the silicone-based-soft liners ${ }^{[13]}$. On the other hand, sandblasting had a weakening effect on the bond. Silica coating and silane surface treatments did not improve the bond strength with the silicone-based soft liner ${ }^{[14]}$.

The use of nanoparticles has a significant improvement in the denture's physical and mechanical properties and reduces bacterial adhesion. It has attracted the researchers to study the impact of nanoparticles on prosthetic materials nowadays [15]. Hydroxyapatite-collagen system bone grafts nanoparticles facilitate bone cell growth and tissue formation because of its composition and similarity to the bone ${ }^{[16]}$. Nanofillers included in the vinyl polysiloxanes impression materials provide a better flow of the material, improved hydrophilic properties, and high precision of the impression details ${ }^{[17]}$. Desensitizing agents containing carbonate-apatite nanoparticles can effectively seal the dentinal tu- 
bules without adversely affecting the bonding agent's action to the dentin. Metal oxide nanoparticles have various applications in the dental and research field because of their unique physical and chemical properties, biological properties, and functionality due to their nano-scale size. They have attracted the researcher's interest ${ }^{[18]}$. Aluminum oxide, titanium oxide, and silica fillers can improve the flexural resistance and thermal conductivity of the heat-cured acrylic denture bases that, in turn, may increase patient satisfaction ${ }^{[19,20]}$. The search hypothesis is that metal oxide nanoparticles addition to the heat-cured acrylic resin denture does not affect the peel bond strength with the silicon-soft liner.

\section{AIM OF THE STUDY}

The aim of this study was to evaluate the effect of different nanoparticles (Titanium oxide, aluminum oxide, silica) incorporated in heat cured acrylic resin denture base with different concentrations $(0.1 \%, 0.3 \%$, and $0.5 \%)$ on the bond strength to a denture liner.

\section{MATERIALS AND METHODS}

\section{Sample grouping}

A power analysis was performed based on a previous study ${ }^{[21]}$ using $G^{*}$ Power software (v3.1.9.2) to calculate the sample size. The power value was $95 \%$, and the $\alpha$ level of significance was 0.05 . The results showed an effect size of $f=1.251$, no centrality parameter of 31.343 , a critical $F$ value of 3.05 , and the calculated sample size was ten. A total number of 100 samples were selected and classified into a control group, which had a ten heat-cured acrylic resin samples without nanoparticles, and three groups according to the type of nanoparticle filler inside the denture base. Group I, which had a titanium oxide nanoparticle. Group
II and III, which had aluminum oxide (alumina) and silica nanoparticles, respectively. Groups I, II, and III were further divided into three subgroups (ten samples per each subgroup) according to the denture base's nanoparticle concentration. Subgroup (A): The denture base had a $0.1 \%$ concentration of nanoparticles. And subgroups (B) \& (C) where the denture base had $0.3 \%$ and $0.5 \%$ concentration of nanoparticles respectively.

\section{Nanoparticle preparation}

The study was conducted between December 2019 and August 2020. Nanoparticles were prepared in nanomaterials laboratory (Nanogate Laboratory, Cairo, Egypt). Specimens were fabricated at a prosthodontics laboratory and tested at the research laboratory, Faculty of Dental Medicine, Al-Azhar University, Cairo, Egypt. Nanomaterials were prepared by the sol-gel method. For the silica nanoparticle, the preparation was done by the drop-wise addition of hydrochloric acid in a sodium silicate aqueous solution. The alumina nanoparticles were prepared from aluminum nitrate precursor and ammonium carbonate. The titanium oxide nanoparticles were prepared by precipitation of homogeneous titanium (IV) isopropoxide solution as a precursor in an aqueous solution of nitric acid with a $\mathrm{pH}$ of (2) using a water-to-titanium mole ratio of 200. Transmission electron microscope analysis for nanoparticle was done by a high-resolution transmission electron microscope (JEM-2100, Jeol, Akishima, Japan) at an accelerating voltage of $200 \mathrm{kV}$ (Figure 1). An X-ray diffraction analysis has been used to analyze the structure of crystalline material. It was performed using a powder diffractometer system (X'pertPro-Panalytical, Malvern, United Kingdom) using a different " 2 theta" angles $20^{\circ}$ and $80^{\circ}$, and at a wavelength $(\mathrm{K} \alpha)=1.54614^{\circ}$. The nanoparticles were added to the heat-cured acrylic resin monomer with the desired concentration by volume (v/v \%). 


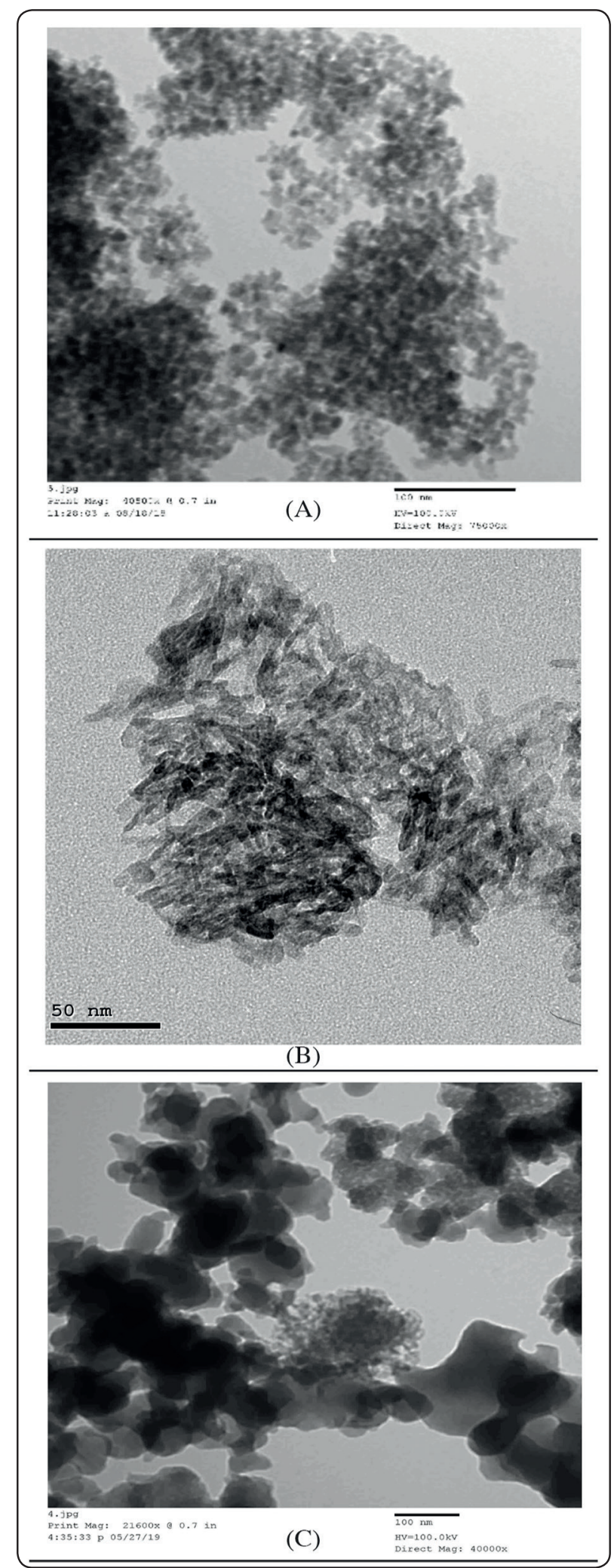

Fig. (1) Scanning electron microscope of different nanoparticles. A: Titanium oxide nanoparticles. B: Aluminum oxide nanoparticles, C: silica nanoparticles.

\section{Fabrication of acrylic resin specimens}

The samples dimension was $64 \times 10 \times 3.3 \mathrm{~mm}$ according to ISO standard number 20795-1:2013. A metallic mold was prepared to standardize the samples' wax pattern size (Cavex set-up Regular, Cavex, Haarlem, Holland). Wax pattern with the specified dimensions was cut and coated with a separating medium and invested by plaster in the flask. Then the wax was eliminated by the immersion of the mold in boiling water for 4 minutes. Heatcured acrylic resin denture base (Acrostone heatcured denture base, Acrostone, Cairo, Egypt) was measured according to the manufacturer's instructions by volume. The polymer to the monomer containing nanoparticle ratio was 3:1. The material was mixed until reaching the dough stage and packed inside the mold. Then the flask was closed and placed under pressure. The material was cured by inserting the flasks in a $75^{\circ} \mathrm{C}$ water bath for 2 hours then to $100^{\circ} \mathrm{C}$ for another 1 hour and 30 minutes. The specimens were removed from the mold.

\section{Fabrication of the soft liner}

Wax pattern with $3 \mathrm{~mm}$ thickness was applied over the acrylic resin specimens and coated with a separating medium. The acrylic resin specimen with the overlying wax was invested by silicone putty (Zeta plus, Zhermack, Polesine, Italy) in a flask to provide space for the soft lining materials. Then the wax was removed from the acrylic resin and cleaned from any traces of the wax. The liner adhesive was painted on the acrylic resin and left for 1 minute. The denture liner (Mollosil, Detax GmbH, Ettlingen, Germany) was mixed using the gun and applied over the acrylic resin. Then the flask was closed again for 6 minutes and 30 seconds until the setting of the soft liner. The specimens were removed from the flask and cleaned from any softliner flashes. 


\section{Peel bond strength measurement}

The bond strength was measured by the peel bond strength test at an angle of $90^{\circ}$ using a universal testing machine with a load cell of $5 \mathrm{kN}$ (Model 3345, Instron Industrial Products, Norwood, USA). Each sample was mounted horizontally on the lower fixed compartment of the testing machine by tightening screws through a base with adjustable jaws. A portion of the soft liner was lifted upwards and attached to the Jackob chuck of the upper movable compartment of the testing machine at $20 \mathrm{~mm}$ from the test specimen's adhesive bond area. The peeling test was done by subjecting the test specimen to tension to promote the resilient liner's peeling from the heat-curing acrylic resin base at a $5 \mathrm{~mm} / \mathrm{min}$ speed until failure occurred. A load of failure was recorded in Newton using computer software (Bluehill Lite; Instron Industrial Products, Norwood, USA). The load at failure was divided by the bonding area to express the bond strength in MPa. The formula of bond strength $(\mathrm{MPa})=\mathrm{P} / \mathrm{A}(\mathrm{P}=$ load at failure, $\mathrm{A}=$ interfacial area between liner and acrylic base.

\section{Statistical analysis}

Data were analyzed using a commercially SPSSC program (Chicago, IL, USA version 20 for windows). Kolmogorov Smirnov test showed a normal distribution of data. Two-way ANOVA followed by the post-hoc turkey test for the interaction between the peel bond strength versus the different nanoparticle groups and subgroups concentrations $(\mathrm{p}<0.05)$.

\section{RESULTS}

The mean and standard deviation of peel bond strength are shown in table (1) and figure (2). For the Control group, the peel bond strength was $0.045918 \pm 0.012054 \mathrm{MPa}$. For Group I-Subgroup $\mathrm{A}, \mathrm{B}$, and $\mathrm{C}$, the peel bond strength was 0.086338 $\pm 0.05034 \mathrm{MPa}, 0.12944 \pm 0.03646 \mathrm{MPa}, 0.096918$ $\pm 0.033871 \mathrm{MPa}$, respectively. For Group II-Subgroup $\mathrm{A}, \mathrm{B}$, and $\mathrm{C}$, the peel bond strength was
$0.069885 \pm 0.029667 \mathrm{MPa}, \quad 0.087525 \pm 0.020571$ $\mathrm{MPa}, \quad 0.076523 \pm 0.028915 \mathrm{MPa}$, respectively. For Group III-Subgroup A, B, and C, the peel bond strength was $0.105345 \pm 0.04957 \mathrm{MPa}$, $0.090923 \pm 0.026992 \mathrm{MPa}, \quad 0.098948 \pm 0.028579$ $\mathrm{MPa}$, respectively.

Two-way ANOVA interaction between the nanomaterial and the peel bond strength showed a non-significant difference between the control and group I, II, and III. This result indicates that the metal oxide nanoparticles in this study did not affect the peel bond strength (table 2) (p <0.05). The interaction between concentration versus peel bond showed a non-significant difference between the control group, subgroup A, B, and C. This result means that increasing the metal oxide concentrations in this study did not affect the peel bond strength $(\mathrm{p}<0.05)$.

TABLE (1) Mean and Standard deviation of peel bond strength values $(\mathrm{MPa})$

\begin{tabular}{|c|c|c|c|}
\hline & Group I & Group II & Group III \\
\cline { 2 - 4 } & \multicolumn{3}{|c|}{ (Mean \pm SD) } \\
\hline Subgroup A & $0.086 \pm 0.050$ & $0.069 \pm 0.029$ & $0.105 \pm 0.049$ \\
\hline Subgroup B & $0.129 \pm 0.036$ & $0.087 \pm 0.020$ & $0.090 \pm 0.026$ \\
\hline Subgroup C & $0.096 \pm 0.033$ & $0.076 \pm 0.028$ & $0.098 \pm 0.028$ \\
\hline Control & \multicolumn{3}{|c|}{$0.045 \pm 0.0120$} \\
\hline
\end{tabular}

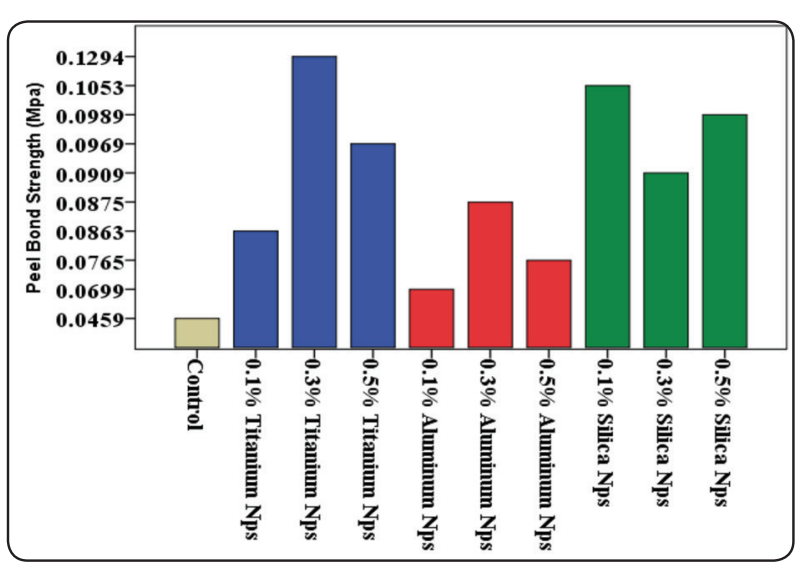

Fig. (2) Bar chart of mean values of peel bond strength values of different materials of this study in (Mpa). 
TABLE (2) Two-way ANOVA of the effect of the studied nanomaterial and their concentration on the peel bond strength of the silicone-based soft liner $<0.05$ ).

\begin{tabular}{|c|c|c|c|c|c|}
\hline \multicolumn{6}{|c|}{ Tests of between-samples effects } \\
\hline \multirow{5}{*}{ Dependent Variable: Bond } & $\begin{array}{c}\text { Type III } \\
\text { Sum of } \\
\text { Squares }\end{array}$ & Df & $\begin{array}{c}\text { Mean } \\
\text { Square }\end{array}$ & F & Sig. \\
\hline $\begin{array}{c}\text { Corrected } \\
\text { Model }\end{array}$ & $57.681 \mathrm{a}$ & 9 & 6.409 & 54.481 & .000 \\
\hline Intercept & 30.672 & 1 & 30.672 & 260.726 & .000 \\
\hline Concentration & .002 & 2 & .001 & .008 & .992 \\
\hline Nanomaterial & .006 & 2 & .003 & .024 & .976 \\
\hline
\end{tabular}

a. $R$ Squared $=.925$ (Adjusted $R$ Squared $=.908)$

\section{DISCUSSION}

The use of the soft-liner has gained much attention in prosthodontics. However, failure of the bonding between the denture base and the soft liner is the main drawback to the soft liners' effectiveness. ${ }^{[22]}$. Silicone-based soft liners have a little to no chemical adhesion to the acrylic denture base due to the different chemical composition between them with subsequent microleakage ${ }^{[23]}$. Different approaches were used to study the soft liners' adhesion to the denture base polymers such as peel, shear, and tensile tests. However, there is no general agreement on a test method used to assess denture liner's bond strength to the denture base ${ }^{[24]}$. Testing the soft liners' adhesion to hard surface faces some technical difficulties that arise mainly from the low tear strengths of the soft liner. The soft liner's rupture usually occurs during debonding the soft liner from the base surface during the test. It has been reported that cohesive failures occur during the tearing of the soft liner ${ }^{[25]}$. The stresses applied to the specimen in shear testing are concentrated at the edges of the lining material. It can complicate the analysis of the bond strength and the explanation of the mechanisms of failure. The shear strength of the bond is also affected by the component materials' deformation values that make the situation even more complicated due to the varying viscoelastic properties of different relining material ${ }^{[26]}$. In the present study, the peel test was used to test the bond strength of soft liner with denture base resin. It has been reported that the peel test is the best indicator of clinical failure for soft liner material because the debonding of the soft-liner starts at the exposed edge clinically ${ }^{[27]}$.

In the present study, metal oxides nanoparticles (Titanium oxide, aluminum oxide, and silica) with different concentrations $(0.1 \%, 0.3 \%$, and $0.5 \%)$ reinforcement for heat-cured acrylic resin did not affect the peel bond strength with silicone-based soft liner. This study results also show a closer result to a study that revealed a non-significant difference in the shear bond strength of heat-cured acrylic resin with the acrylic based-soft liner reinforced by $2 \%$ titanium oxide nanoparticles ${ }^{[28]}$. On the other hand, the current study results disagree with the results of another study where the addition of $2 \%$ silanated alumina and 5\% silica nanoparticles to the denture base significantly increases the bond strength between the heat-cured acrylic resin denture base and the heat-cured acrylic denture liner ${ }^{[29]}$. The bond strength improvement because of soft liner because the denture base and the soft liner have the same chemical composition, and the addition of the silane coupling agent increases the bond strength ${ }^{[30]}$.

The increase in the soft-liner bonding to the acrylic resin may be attributed to good dispersion of nanoparticles in the polymer matrix with strong inter-atomic ionic bonding by the van der walls forces between the nanoparticles and the polymer matrix. The result is an increase in the polymer chain's cross-linking with limitation of the polymer mobility and dense polymer matrix composite ${ }^{[31]}$.

In the present study, the non-significant effect of nanoparticles on peel bond strength between the 
heat-cured denture base and the soft liner may be explained by the low concentration of nanoparticles, which causes a lesser bonding between the nanofillers and resin matrix. The water absorption directly decreases the bonding strength; it causes swelling of polymers in the bonding interface and, consequently, buildup stress at the interface leading. Also, the leaching out of plasticizer into water will leave empty spaces that reduce the cushioning effect, transmit the internal loads to the bonding interface ${ }^{[32]}$. On the other hand, Excessive nanoparticle may decrease the degree of polymer conversion of the heat-cured acrylic resin denture base. The residual monomer is caught inside the polymer network and functions as a plasticizer ${ }^{[33]}$. There is a strong correlation between the amount of residual monomer and water sorption in the acrylic resin denture base ${ }^{[34]}$. The amount of residual monomer in the acrylic resin denture can potentially affect the polymer's cross-linkage at the interface between the base acrylic resin and the soft liner ${ }^{[35]}$. Some investigations found adverse effects on heat-cured acrylic resin's mechanical properties when the nanoparticles concentrations were above $1 \%$ concentration. ${ }^{[36,37]}$

This study has limitations; first: The analysis was performed at room temperature. A dental prosthesis temperature can differ considerably during clinical use due to the ingestion of hot and cold foods and beverages and warm or hot water used to clean the prosthesis. As a result, The amount of water sorption of both the denture base and liner increases [38]. Second: broader concentrations and various materials must be assessed. Third: The selected concentrations must be studied for their biosafety when incorporated in the denture base. Since nanomaterials are similar in size to DNA molecules, viruses, proteins, and biological molecules, their effects and interactions with the living tissue have not fully understood yet. Many safe materials showed neural and cellular toxicity when they are reduced to nanoparticles ${ }^{[39]}$.

\section{CONCLUSION}

Within the limitation of this study, the result showed that the addition of titanium oxide, aluminum oxide, and silica nanoparticles with $0.1 \%, 0.3 \%$, and $0.5 \%$ concentration to acrylic denture base didn't significantly increase the peel bond strength to the silicon-based soft liner regardless of their type and concentration.

Conflict of interest: None declared.

\section{REFERENCES}

1. Shim J, Watts D. (2000). An examination of the stress distribution in a soft-lined acrylic resin mandibular complete denture by finite element analysis. Int $\mathrm{J}$ Prosthodont 13, 19-24

2. Kimoto S, Kimoto K, Gunji A, Kawai Y, Murakami H, Tanaka K, et al. (2007). Clinical effects of acrylic resilient denture liners applied to mandibular complete dentures on the alveolar ridge. J Oral Rehabil 34, 862-869

3. Kasuga Y, Takahashi H, Akiba N, Minakuchi S, Matsushita N, Hishimoto M. (2011). Basic evaluation on physical properties of experimental fluorinated soft lining materials. Dent Mater J 30, 45-51

4. Yoeli Z, Miller V, Zeltser C. (1996). Consistency and softness of soft liners. J Prosthet Dent 75, 412-418

5. Hekimoglu C, Anil N. (1999). The effect of accelerated ageing on the mechanical properties of soft denture lining materials. J Oral Rehabil 26, 745-748

6. Chladek G, Kasperski J, Barszczewska I, Zmudzki J. (2012). Sorption, solubility, bond strength and hardness of denture soft lining incorporated with silver nanoparticles. Int J Mol Sci 14, 563-574

7. Saravanan M, Kumar A, Padmanabhan T, Banu F. (2015). Viscoelastic properties and antimicrobial effects of soft liners with silver zeolite in complete dental prosthesis wearers: an in vivo study. Int J Prosthodont 28, 265-269

8. Sinobad D, Murphy W, Huggett R, Brooks S. (1992). Bond strength and rupture properties of some soft denture liners. J Oral Rehabil 19, 151-160

9. Mese A, Guzel K, Uysal E. (2005). Effect of storage duration on tensile bond strength of acrylic or silicone-based soft denture liners to a processed denture base polymer. Acta Odontol Scand 63, 31-35 
10. Shetty S, Guttal S. (2012). Evaluation of bonding efficiency between facial silicone and acrylic resin using different bonding agents and surface alterations. J Adv Prosthodont 4, 121-126

11. McMordie, King G. (1989). Evaluation of primers used for bonding silicone to denture base material. J Prosthet Dent 61, 636-639

12. Kantola R, Lassila L, Vallittu P. (2011). Adhesion of maxillofacial silicone elastomer to a fiber-reinforced composite resin framework. Int J Prosthodont 24, 582-588

13. Haghi H, Shiehzadeh M, Gharechahi J, Nodehi D, Karazhian A. (2020). Comparison of Tensile Bond Strength of Soft Liners to an Acrylic Resin Denture Base with Various Curing Methods and Surface Treatments. Int J Prosthodont $33,56-62$

14. Atsu S, Keskin Y. (2013). Effect of silica coating and silane surface treatment on the bond strength of soft denture liner to denture base material. J Appl Oral Sci 21, 300-306

15. Wang W, Liao S, Zhu Y, Liu M, Zhao Q, Fu Y. (2015). Recent applications of nanomaterials in prosthodontics. J Nanomater 1, 1-11

16. Tautzenberger A, Kovtun A, Ignatius A. (2012). Nanoparticles and their potential for application in bone. Int $\mathrm{J}$ Nanomed 7, 4545-4557

17. Sheta M, El-Shorbagy Z, Abdel-Karim U, Abd-Alla S. (2017). Laboratory comparative study of wettability, dimensional changes, flexibility and tear resistance of two recent elastomeric impression materials. Tant Dent J 14, 89-95

18. Mohamed I. (2012). Current perspectives of nanoparticles in medical and dental biomaterials. J Biomed Res 26, 143-151

19. Kul E, Aladag L, Yesildal R. (2016). Evaluation of thermal conductivity and flexural strength properties of poly(methyl methacrylate) denture base material reinforced with different fillers. J Prosthet Dent 116, 803-810

20. Ellakwa A, Morsy M, El-Sheikh A. (2008). Effect of aluminum oxide addition on the flexural strength and thermal diffusivity of heat-polymerized acrylic resin. J Prosthodont 17, 439-444

21. Habibzadeh S, Omidvaran A, Eskandarion S, Shamshiri A. (2020). Effect of incorporation of silver nanoparticles on the tensile bond strength of a long term soft denture liner. Eur J Dent 14, 268-273

22. Khan Z, Martin J, Collard S. (1989). Adhesion characteristics of visible light-cured denture base material bonded to resilient lining materials. J Prosthet Dent 62, 196-200
23. Surapaneni H, Ariga P, Haribabu R, Ravi Y, Attili S. (2013). Comparative evaluation of tensile bond strength between silicon soft liners and processed denture base resin conditioned by three modes of surface treatment: An invitro study. J Ind Prosth Soc 13, 274-280

24. Mutluay M, Ruyter I. (2005). Evaluation of adhesion of chairside hard relining materials to denture base polymers. J Prosthet Dent 94, 445-452

25. ASTM Committee (1998). ASM standard test methods for rubber property - adhesion to rigid substrates. West Conshohocken, USA.

26. Athel M, Jagger R. (1996). Effect of test method on the bond strength of a silicone resilient denture lining material. J Prosthet Dent 76, 535-540

27. McCabe J, Carrick T, Kamohara H. (2002). Adhesive bond strength and compliance for denture soft lining materials. Biomater 23, 1347-1352

28. Ahmed A, Ali M. (2018). The Influence of Titanium Dioxide Nanoparticles Incorporation into Soft Denture Lining Material on Candida albicans Adherence and Some Mechanical and Physical Properties. J Pure Appl Microbiol 12, 783-791

29. Judy H. (2017). The influence of silica dioxide and aluminum oxide nano fillers reinforced heat cured acrylic denture base material and thermocycling on tensile and shear bond to denture soft lining material. Mustansiria Dent J 14, 99-109

30. Sideridou I, Karabela M. (2009). Effect of the amount of 3-methacyloxypropyltrimethoxysilane coupling agent on physical properties of dental resin nanocomposites. Dent Mater 25, 1315-1324

31. Sun L, Gibson R, Gordaninejad F, Suhr J. (2009). Energy absorption capability of nanocomposites: A review. Compos Sci Technol 69, 2392-2409

32. Elias C, Henriques F. (2007). Effect of thermocycling on the tensile and shear bond strengths of three soft liners to a denture base resin. J Appl Oral Sci 15, 18-23

33. Shibata T, Hamada N, Kimoto K, Sawada T, Sawada T, Kumada H, et al. (2007). Antifungal effect of acrylic resin containing apatite-coated tio photocatalyst. Dent Mater J 26, 437-444

34. Pfeiffer P, Rosenbauer E. (2004). Residual methyl methacrylate monomer, water sorption, and water solubility of hypoallergenic denture base materials. J Prosthet Dent 92, 72-78

35. Rajaganesh N, Sabarinathan S, Azhagarasan N, Shankar C, Krishnakumar J, Swathi S. (2016). Comparative evalu- 
ation of shear bond strength of two different chairside soft liners to heat processed acrylic denture base resin: An in vitro study. J Pharm Bioallied Sci 8, S154-S159

36. Lee J, El-Fiqi A, Jo J, Dong-AeKim. (2016). Development of long-term antimicrobial poly(methyl methacrylate) by incorporating mesoporous silica nanocarriers. Dent Mater $32,1564-1574$

37. Sodagar A, Bahador A, Khalil S, Shahroudi A, Kassaee M. (2013). The effect of $\mathrm{TiO} 2$ and $\mathrm{SiO} 2$ nanoparticles on flex- ural strength of poly (methyl methacrylate) acrylic resins. J Prosthodont Res 57, 15-19

38. Neppelenbroek K, Pavarina A, Gomes M, Machado A, Vergani C. (2006). Bond strength of hard chairside reline resins to a rapid polymerizing denture base resin before and after thermal cycling. J Appl Oral Sci 14, 436-442

39. Feng X, Chen A, Zhang Y, Wang J, Shao L, Wei L. (2015). Application of dental nanomaterials: potential toxicity to the central nervous system. Int J Nanomed 10, 3547-3565 